\title{
Synthesis and optical characteristics of silver nanoparticles on different substrates
}

\author{
Narender Budhiraja ${ }^{1, *}$, Ashwani Sharma ${ }^{1}$, Sanjay Dahiya ${ }^{1}$, Rajesh Parmar $^{1}$, \\ Viji Vidyadharan ${ }^{2}$ \\ 1 Department of Physics, Maharshi Dayanand University, Rohtak - 124001, Haryana, India \\ ${ }^{2}$ School of Pure \& Applied Physics, Mahatma Gandhi University, Kottayam, Kerala, India \\ *E-mail address: narenderarora1988@gmail.com
}

\begin{abstract}
Silver nanoparticles have been deposited on glass and polyethylene substrate by Chemical Bath Deposition (CBD) technique and Chemical rolling method. A comparative study has shown that Chemical bath technique is superior compared to rolling technique for uniform deposition of silver nanoparticles on glass substrate. Crystallography investigation of these materials is done by X-ray diffraction (XRD) which reveals that average grain size is in nano region. Scanning Electron Microscope (SEM) is used for topography study of these prepared nanostructures. Optical properties of the synthesized materials are studied by UV-VIS in detail to check their potential for next era industrial revolution.
\end{abstract}

Keywords: Nanoparticle; Crystallography; Topography; XRD; SEM; UV-VIS

\section{INTRODUCTION}

Nanostructured silver particles exhibit unique optical characteristics. In contrast to their corresponding bulk counterparts, metallic nanoparticles can absorb electromagnetic radiation, resulting in surface plasmon polaritons at the metal dielectric interface. Silver nanoparticles are also frequently used to modify various organic and inorganic substrates to obtain materials of novel properties. However, most of practical applications of silver nanoparticles involve thin films deposition on various solid surfaces. Such films can serve as catalytic materials. Nanocrystalline silver particles have found tremendous applications in the field of high sensitivity biomolecular detection and diagnostics, antimicrobials and therapeutics, micro-electronics [1-5]. As Silver products have long been known to have strong inhibitory and bactericidal effects, as well as a broad spectrum of antimicrobial activities, which has been used for centuries to prevent and treat various diseases, most notably infections. Silver nanoparticles are reported to possess anti-fungal, anti-inflammatory, anti-viral and antiangiogenesis activity.

A number of approaches are available for the synthesis of silver nanoparticles such as electrochemical method, thermal decomposition, laser ablation, microwave irradiation and sonochemical synthesis [6-10]. However, there is still a need for economic, commercially viable as well environmentally clean route to synthesize silver nanoparticles. Here in, we 
report for the synthesis of silver nanoparticles, reducing the silver ions present in the solution of silver nitrate.

Silver nanowires have been attracting more and more attention because of their intriguing electrical, thermal, and optical properties. Silver has the highest electrical conductivity $(6.3 \times 107 \mathrm{~S} / \mathrm{m})$ among all the metals, by virtue of which Ag NWs are considered as very promising candidates in flexible electronics [11-13]. Since then, Ag NW films have been fabricated using techniques, such as vacuum filtration, transfer printing onto polyethylene substrates, drop casting, and air-spraying from NW suspension. The vacuum filtration method, produces highly transparent films with excellent conductivity[14], but the films possess irregular morphologies and significant roughness. Moreover, the process is not scalable. Using drop casting method always shows circular rings and discontinuous film on the substrates [15-16]. The film obtained from air-spraying coating is much better, but still forms sparse and non-uniform networks. In brief, most of the processes proposed so far cannot be ported easily to large scale production. Moreover, the researches on the film properties and effect factors have been very limited. In this paper, we demonstrate uniform and transparent $\mathrm{Ag}$ film on polyethylene substrate as well as on glass substrate via a scalable, simple, and low-cost process.

\section{EXPERIMENTAL}

\section{1. MATERIALS}

Silver nitrate (A.R.) and polyvinylpyrrolidone (PVP, MW = 40,000) were purchased from Himedia. For the preparation of mixture solution, deionized water was used.

\section{2. Method}

The silver sol was prepared by reduction of $\mathrm{Ag}^{+}$ions using addition of ethyl alcohol containing $2 \% \mathrm{PVP}$ solution. The weight ratios of $\mathrm{AgNO}_{3}$ metal salt to PVP were 1:5.

The glass rod is sonicated in a sonic bath. Then, as prepared suspension was applied to a $50 \mathrm{~mm} \times 100 \mathrm{~mm}$ polyethylene substrates by a manually controlled wire-wound rod i.e., pushing the suspension on top of the substrate with a glass rod. The Ag film looks very uniform over the entire substrate. Same procedure is followed for preparing a silver sol for synthesize nanofilm on glass substrate. The substrate (glass slide) is immersed in the sol of as prepared coating material at a constant uniform speed. After 24 hours substrate is pulled up with same uniform speed. The speed determines the thickness of the coating. Faster withdrawal gives thicker coating material. The glass substrate is placed in vacuum oven for drying the film at $60{ }^{\circ} \mathrm{C}$.

\section{RESULTS AND DISCUSSION}

\section{1. X-Ray diffraction}

XRD can be used to characterize the crystallinity of nanoparticles. The XRD Pattern were obtained using panalytical's Xpert-pro powder diffractometer employing $\mathrm{Cu}-\mathrm{K}_{\alpha}$ radiations in the $2 \theta$ range. 


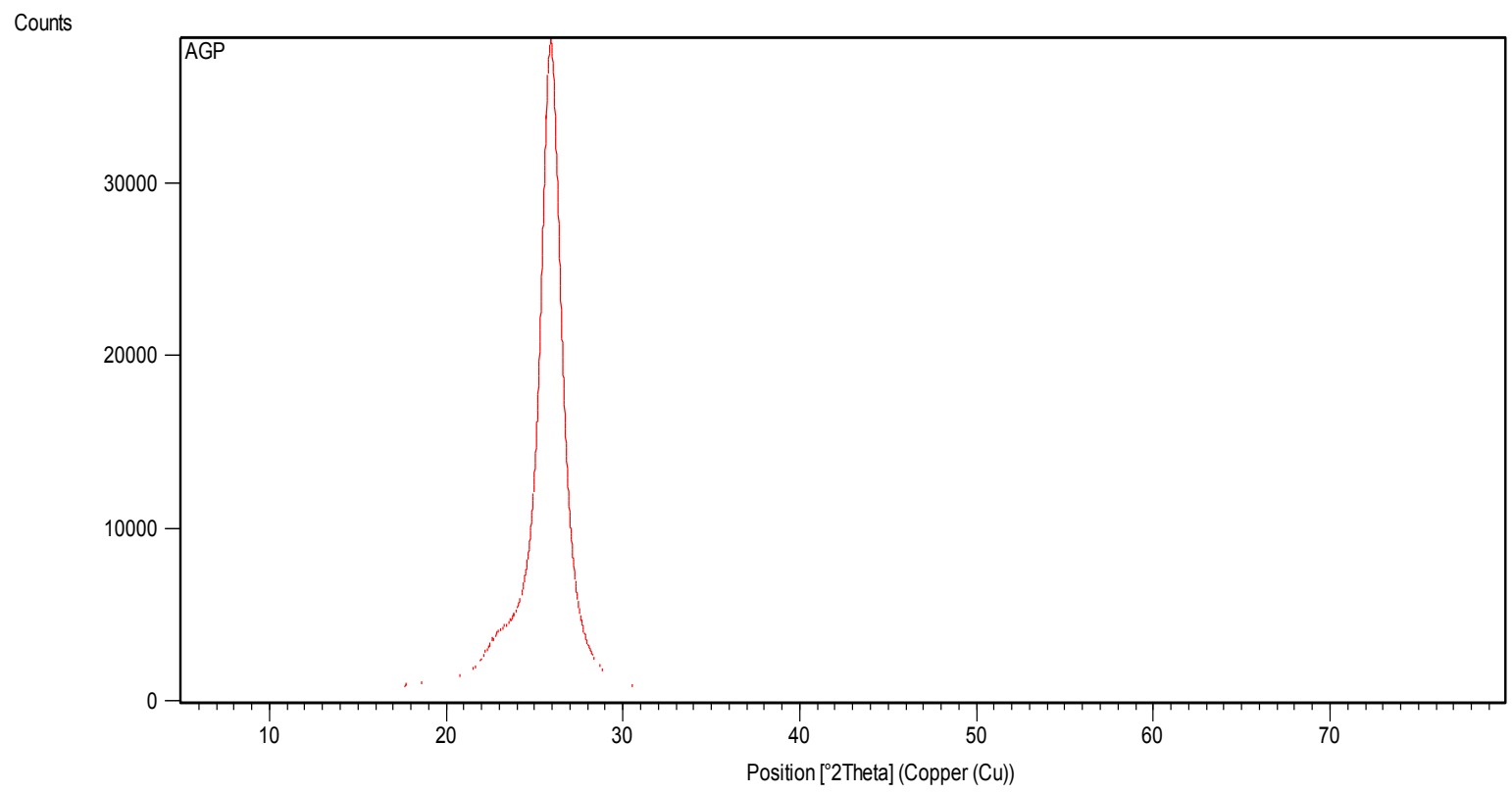

Fig. 1. Shows XRD pattern of synthesized silver nanoparticle on Polyethylene substrate.

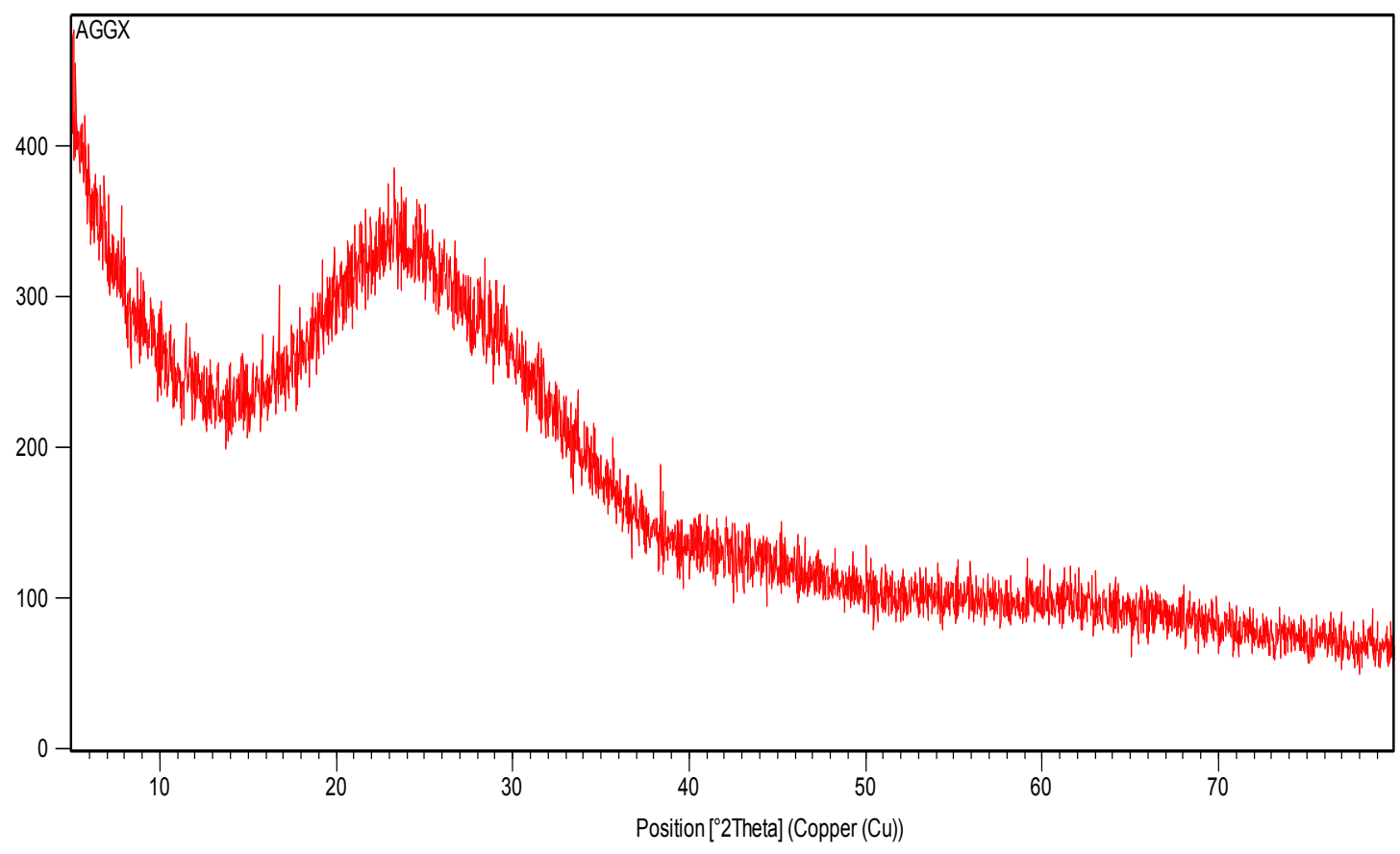

Fig. 2. Shows XRD of synthesized silver nanomaterial on glass substrate.

An XRD pattern of as prepared silver nanoparticle on Polyethylene substrate was given in Fig. 1(a). The particle size of as prepared samples was found using Scherrer formula

$$
\mathrm{d}=0.9 \lambda / \beta \cos \theta
$$


where $d=$ average particle size, $\beta$ is full width at half maxima (FWHM), $\theta$ is the Bragg angle, $\lambda$ is the wavelength of $\mathrm{Cu} \mathrm{K}_{\alpha}$ in radians [17-21]. The average size of silver nanoparticles on thin film on polyethylene substrate comes out to be $7.40 \mathrm{~nm}$. The diffraction data revealed that the material has crystalline Ag nanoparticles.

Fig. 2 shows XRD of synthesized silver nanomaterial on glass substrate. A bump is observed instead of peak corresponding to $2 \theta$ value of 24. 973. The broad peak indicate that the silver nanoparticles thin film on glass substrate is amorphous in nature.

\section{2. UV-VIS. Spectroscopy}

The formation of silver nanoparticles was monitored using UV-VIS absorption spectroscopy [22-28]. For analyzing the band gap of synthesized nanomaterial, the absorption spectra is recorded through Double beam UV-VIS absorption spectrometer in the range of 200-800 nm. Fig. 3 shows UV-VIS absorption spectra of as prepared silver nanoparticles on polyethylene substrate.

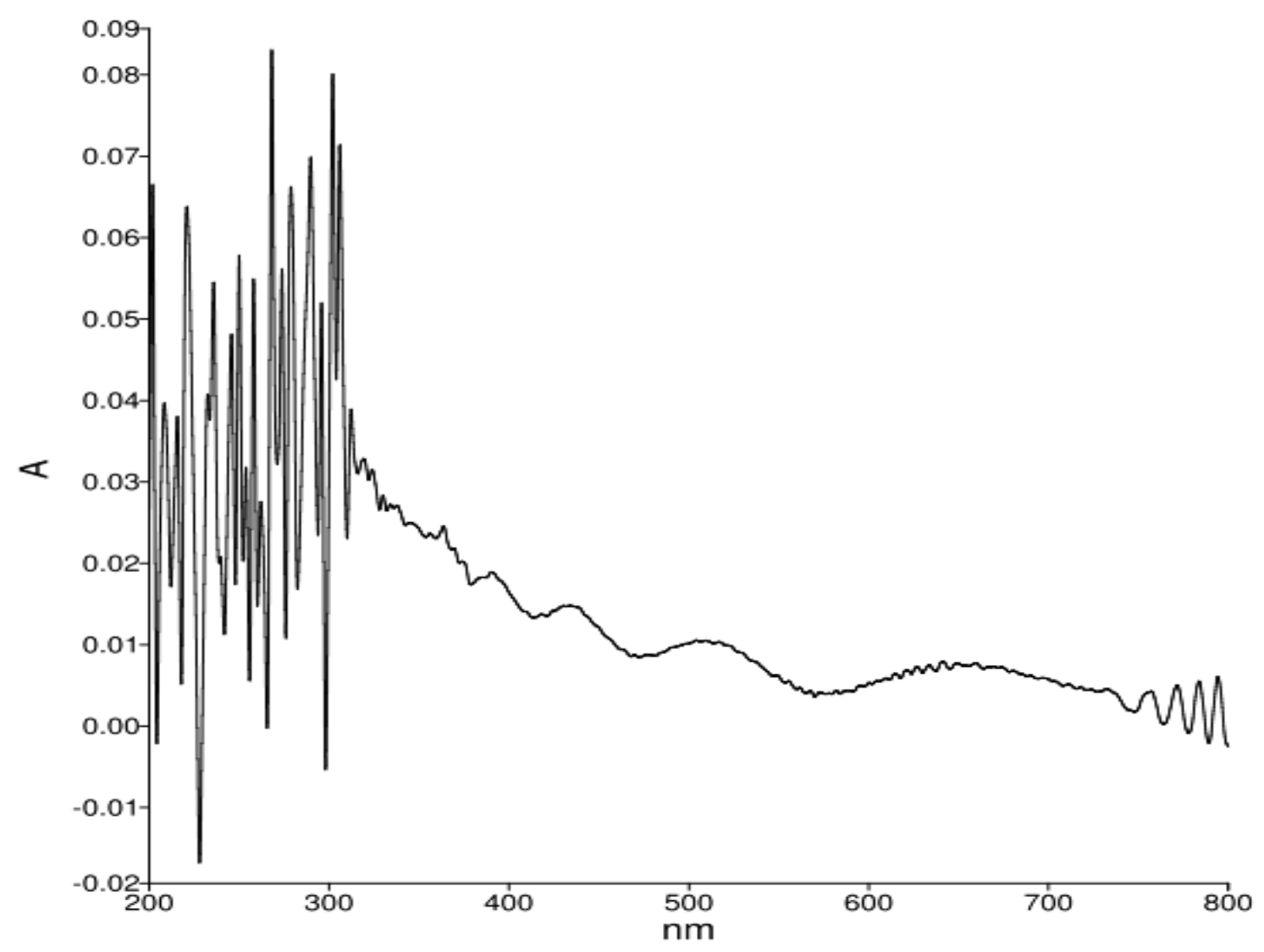

Fig. 3. Shows UV-VIS. absorption spectra of silver nanoparticle on polyethylene substrate.

There are number of intense peaks observed in the ultraviolet region in the range of 200 to $330 \mathrm{~nm}$ and absorption decreases up to $380 \mathrm{~nm}$. In the visible region, absorption further decreases with small peaks at $430 \mathrm{~nm}, 520 \mathrm{~nm}$ and $650 \mathrm{~nm}$. Cut off wavelength in case of silver nanoparticles thin film on polyethylene substrate is $300 \mathrm{~nm}$. The band gap of the silver nanoparticles on polyethylene substrate is calculated on the basis of the formulae as given below: 


$$
\mathrm{Eg}=1240 / \lambda(\mathrm{eV})
$$

which comes out to be $4.13 \mathrm{eV}$.

Similar procedure is followed for evaluating band gap of silver nanoparticle synthesize on glass substrate. Fig. 4 shows UV-VIS. absorption spectra of as prepared silver nanoparticles on glass substrate. The UV- VIS. spectroscopy revealed the formation of silver nanoparticles by exhibiting the typical surface plasma on absorption maxima at $290 \mathrm{~nm}$ for UV-VIS. spectrum. A sharp peak is observed near $290 \mathrm{~nm}$, after which there is sharp decrease in absorption. Then there is sharp increase in absorption and a bump appears on $340 \mathrm{~nm}$ in the ultraviolet region and then it start decreases linearly up to visible region. Cut off wavelength in case of silver nanoparticles thin film on glass substrate is $290 \mathrm{~nm}$. The band gap of the silver nanoparticles on glass substrate is calculated by using the equation (2), which comes out to be $4.27 \mathrm{eV}$.

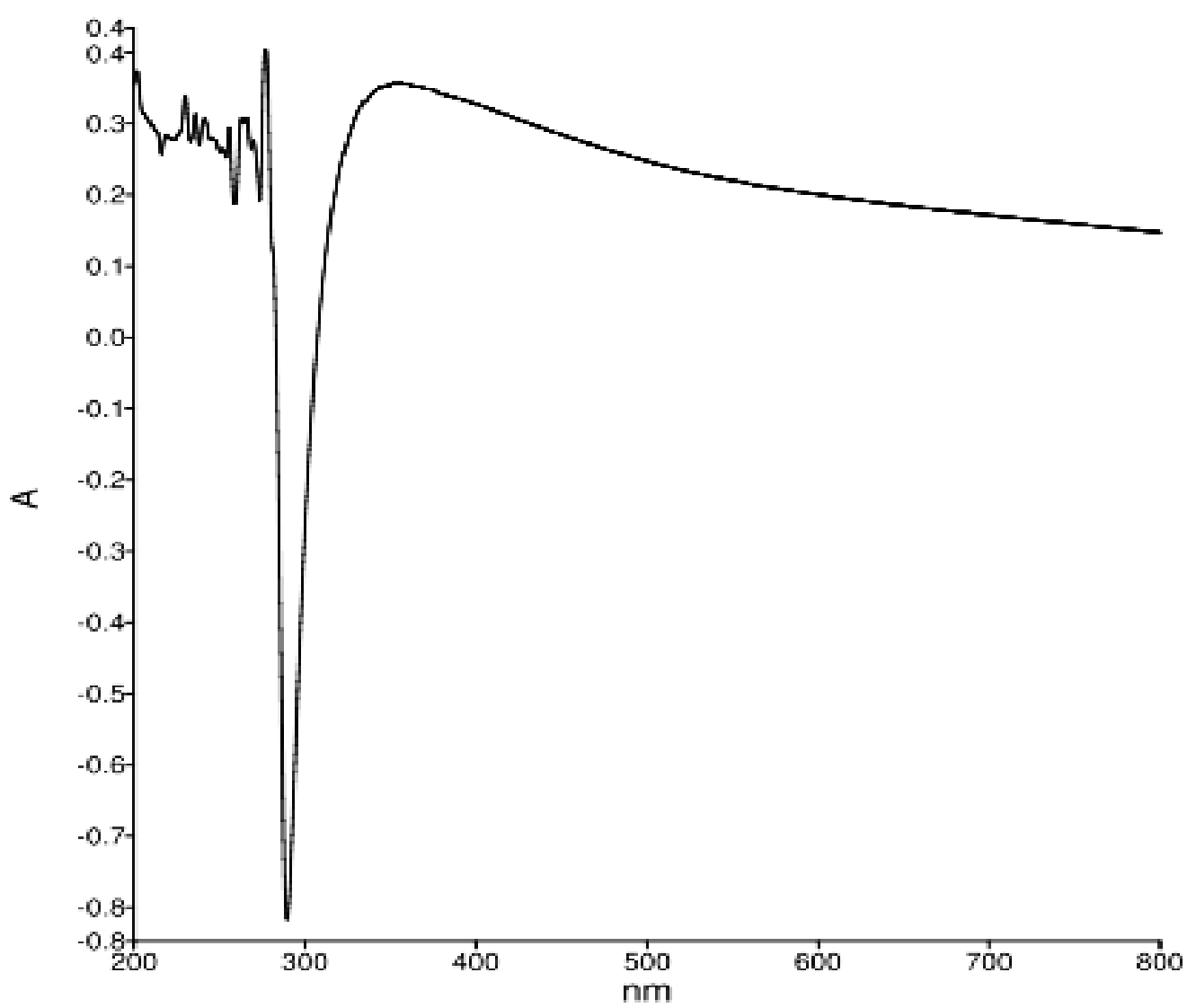

Fig. 4. Shows UV-VIS absorption spectra of silver nanoparticles on glass substrate.

\section{3. Scanning electron microscope (SEM)}

SEM of silver nanoparticles film on polyethylene substrate is shown in Fig. 5 and Fig. 6 at different magnification. 


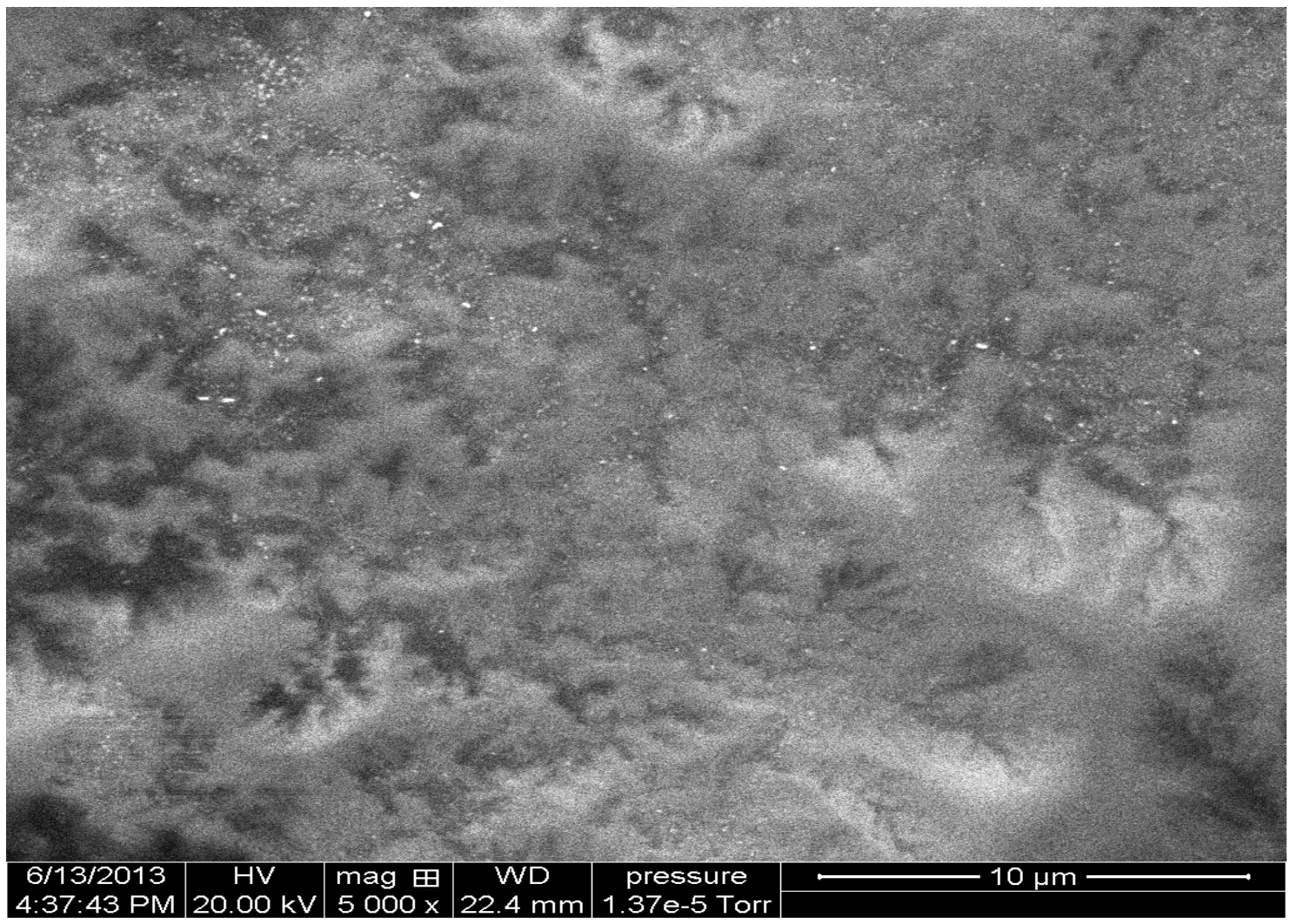

Fig. 5. Shows the SEM image of silver nanomaterial on polyethylene substrate at $5000 \mathrm{X}$ magnification.

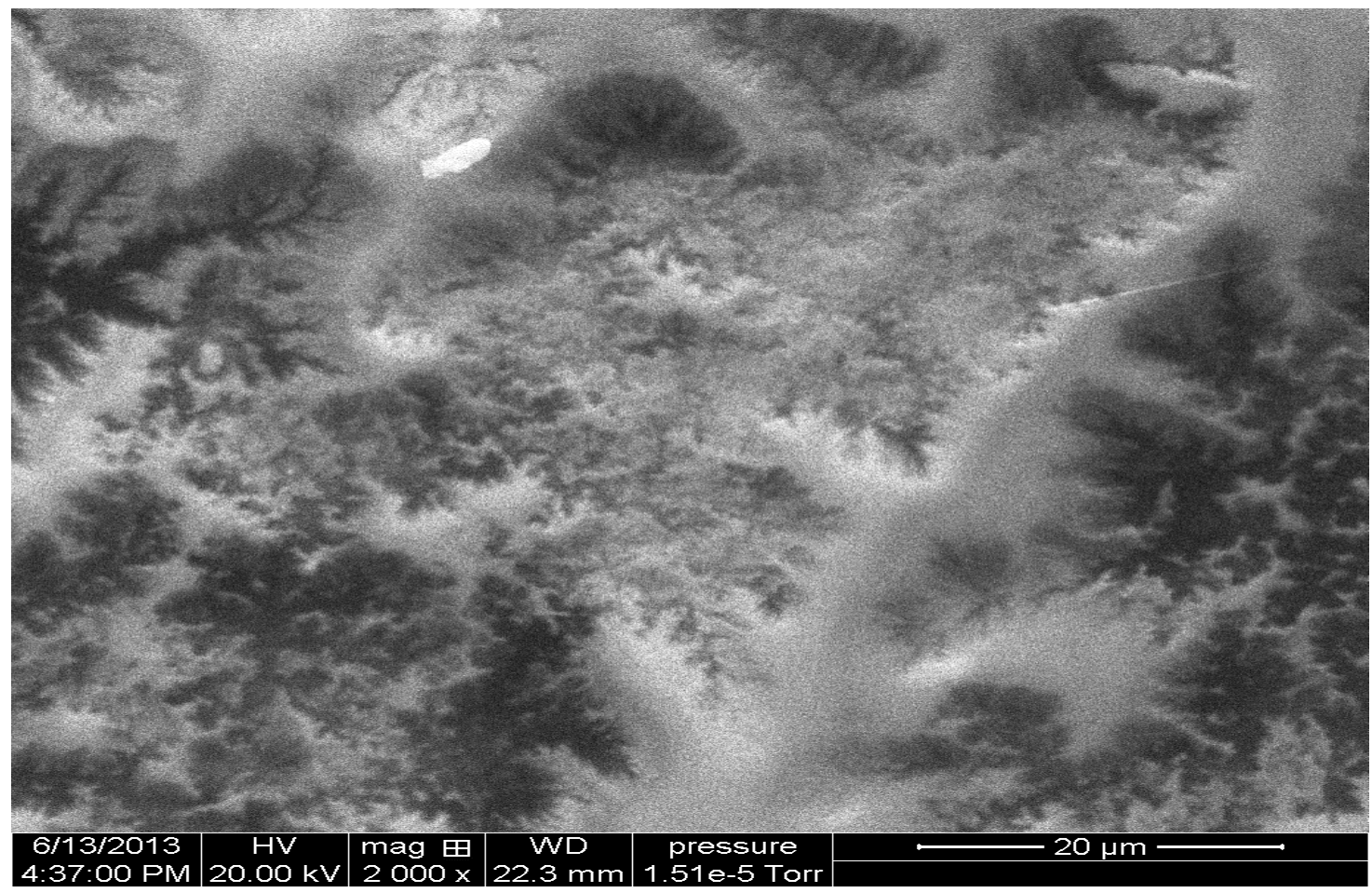

Fig. 6. Shows the SEM image of silver nanomaterial on polyethylene substrate at $2000 \mathrm{X}$ magnification. 


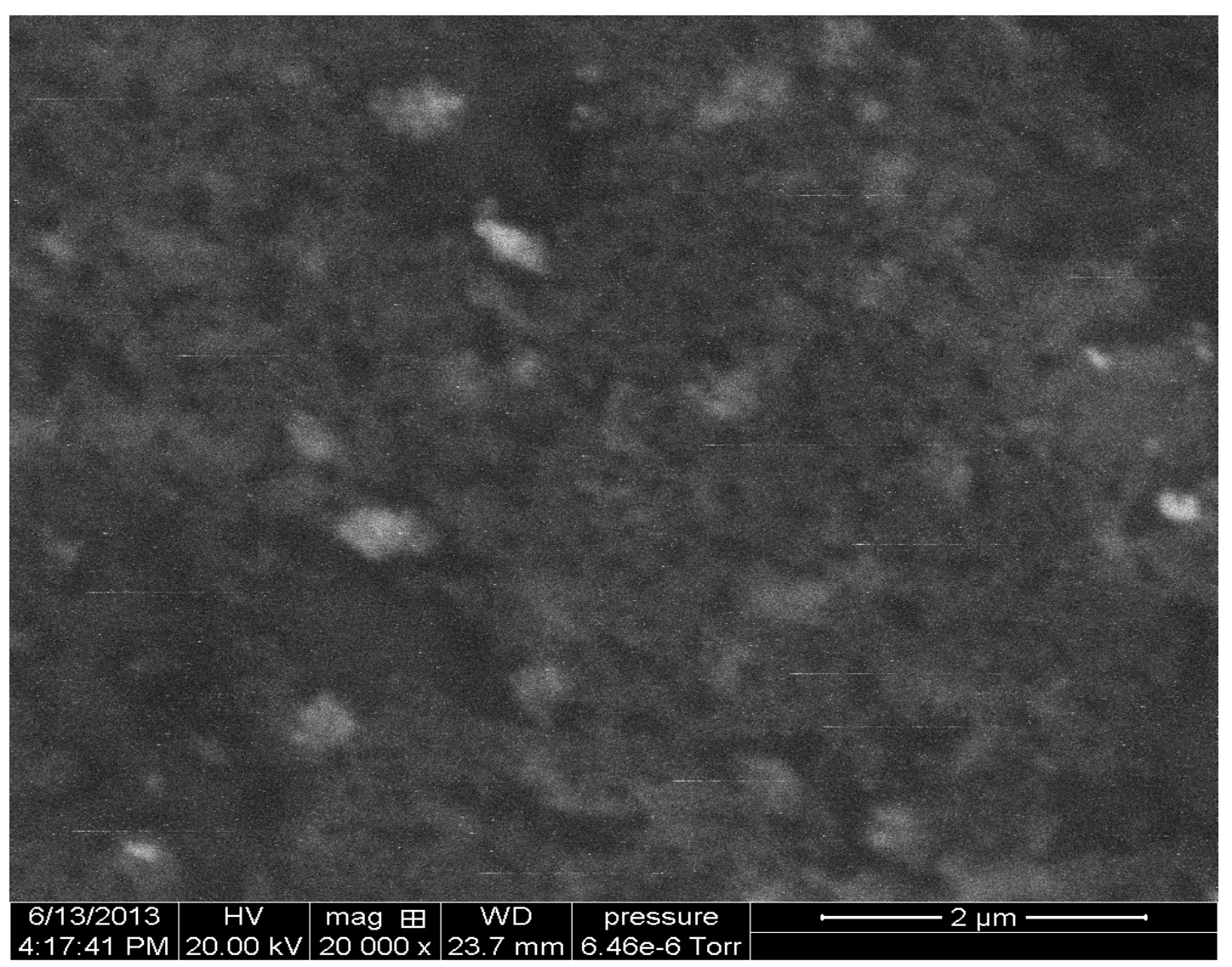

Fig. 7. Shows the SEM image of silver nanomaterial on glass substrate on 20000X magnification.

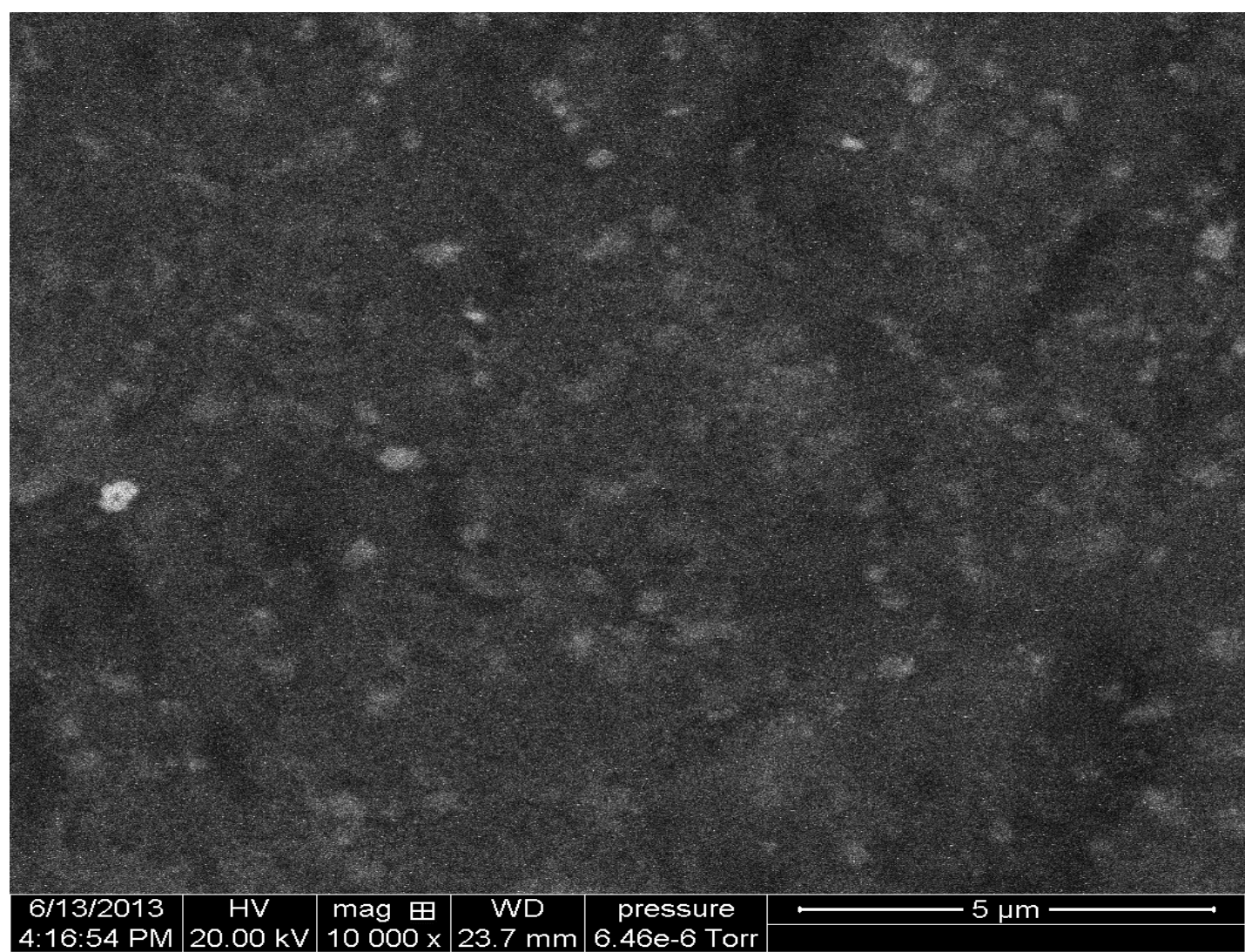

Fig. 8. Shows the SEM image of silver nanomaterial on glass substrate on 10000X magnification. 
Scanning electron microscopy was performed to investigate the morphology of the nanoparticles thin film [29-30]. It is easy to notice that the examined particles consist of a number of smaller objects. The surface of the films shows good uniformity and cracks free, indicating good adhesion and regularity among the thin film layer on the polyethylene substrate. SEM of silver nanoparticles film on glass substrate is shown in Fig. 7 and Fig. 8 at different magnification. On glass substrate, clear mono dispersed and comparatively smaller particles are observed in the SEM micrograph. The SEM image demonstrates clearly the formation of spherical Ag nanoparticles.

\section{4. Ellipsometry spectroscopy}

Ellipsometry spectroscopy is done to measure the thickness of as prepared nanomaterial. Thickness for silver nanoparticles prepared on polyethylene substrate is comes out to be $565.49 \mathrm{~nm}$ (Error: $\pm 8.3 \mathrm{~nm}$ ) nm and those for synthesized on glass substrate is $214.19 \mathrm{~nm}$ ( Error: $\pm 0.7 \mathrm{~nm})$.

\section{CONCLUSIONS}

Thin films of silver nanoparticles were deposited on glass substrate and on polyethylene substrate by Chemical Bath Deposition (CBD) technique and Chemical rolling method. The structural and optical properties of the prepared Ag Nanoparticles thin film on polyethylene and glass have been confirmed using SEM, XRD and UV-VIS. spectroscopy. The thickness of silver nanoparticles thin films carried out by ellipsometry spectroscopy on polyethylene and glass substrate was 565.49 and $214.19 \mathrm{~nm}$. It is observed that the average size of silver nanoparticles on thin film on polyethylene substrate comes out to be $7.40 \mathrm{~nm}$ whereas silver nanoparticles film on glass substrate was amorphous in nature. In UV-VIS. spectra, there is decrease in absorption in visible region on both the substrate. The band gap of silver thin film on polyethylene and glass substrate were 4.13 and $4.27 \mathrm{eV}$.

\section{Acknowledgement}

Author is thankful to UGC for providing the financial support for carrying out research work, to Physics Departemnt, H. P. University Shimla for SEM characterization and SAIF P. U. Chandigarh for XRD and UV-VIS characteristics. Author is thankful to School of Pure \& Applied Physics, Mahatma Gandhi University, Kottayam, Kerala for carrying out thickness of thin films.

\section{References}

[1] S. Schultz , D. R. Smith, J. J. Mock, D. A. Schultz, 2000, PNAS 97, pp. 996-1001.

[2] M. Rai, A. Yadav, A. Gade, Biotechnol, 27 (2009) 76-83.

[3] J. L. Elechiguerra, J. L. Burt, J. R. Morones, A. Camacho-Bragado, X. Gao, H. H. Lara, M. J. Yacaman, J. Nanobiotechnol. 3 (2005) 6-12.

[4] R. M. Crooks, B. I. Lemon, L. Sun, L. K. Yeung, M. Zhao, Curr. Chem. 212 (2001) 82-135.

[5] D. I. Gittins, D. Bethell, R. J. Nichols, D. J. Schiffrin, J. Mater. Chem. 10 (2000) 79-83.

[6] D. V. Goia, E. Matijevic, J. Chem. 22 (1998) 1203-1208. 
[7] C. Taleb, M. Petit, P. Pileni, Chem. Mater. 9 (1997) 950-958.

[8] K. Esumi, T. Tano, K. Torigoe, K. Meguro, Chem. Mater. 2 (1990) 564-573.

[9] A. Henglein, Langmuir 17 (2001) 2329-2334.

[10] L. Rodriguez-Sanchez., M. C. Blanco, M. A. Lopez-Quintela, J. Phys. Chem. B 104 (2000) 9683-9686.

[11] D. Azulai, T. Belenkova, H. Gilon, Z. Barkay, G. Markovich, Nano Lett. 9 (2009) 4246-4249.

[12] Y. Sun, Nanoscale 2 (2010) 1626-1642.

[13] S. De, T. M. Higgins, P. E. Lyons, E. M. Doherty, P. N. Nirmalraj, W. J. Blau, J. J. Boland, J. N. Coleman, Acs Nano 3 (2009) 1767-1774.

[14] J. Y. Lee, S. T. Connor, Y. Cui, P. Peumans, Nano Lett. 10 (2010) 1276-1279.

[15] Y. C. Lu, K. S. Chou, Nanotechnology 21 (2010) 5707.

[16] C. T. Robert, M. B. Teresa, D. B. Jeremy, J. F. Andrew, T. Bobby, M. G. Lynn, J. H. Michael, L. B. Jeffrey, Adv. Mater. 21 (2009) 3210-3216.

[17] M. Epifani, C. Giannini, L. Manna, Materials Letters 58 (2004) 2429-2432.

[18] B. D. Cullity, S. R. Stock, Elements of X-Ray Diffraction, 3rd ed. Prentice Hall, 2001

[19] A. Sharma, Pallavi, S. Kumar, S. Dahiya, N. Budhiraja, Advances in Applied Science Research 4(1) (2013) 124-130.

[20] Patil T. K., M. I. Talele, Pelagia Research Library-Advances in Applied Science Research 3(3) (2012) 1702-1708.

[21] Srikantha, N. Suriyanarayananb, S. Prabahara, V. Balasubramaniana, D. Kathirvelc., Pelagia Research Library-Advances in Applied Science Research 2(1) (2011) 95-104.

[22] Hemissi M., Amardjia-Adnani H., Digest journal of nanomaterials and biostructures 2(4) (2007) 299-305.

[23] S. Suresh, K. Anand, Advances in Applied Science Research 3(2) (2012) 815-820.

[24] M. D. Jeroh, D. N. Okoli, Advances in Applied Science Research 3(2) (2012) 793-800.

[25] D. Y. Godowsky, A. E. Varfolomeev, A. E., Zaretsky, J. Mater. Chem. 11 (2001) 2465-2469.

[26] P. Raji, C. Sanjeeviraja, K. Ramchandran, Cryst. Res. Technol. 39 (2004) 621.

[27] Y. Kayanuma, Phys. Rev. B 85 (1998) 9797-9805.

[28] L. Brus, J. Phys. Chem. 90 (1986) 2555-2560.

[29] K. J. Toda, J. Alloys Comps. 665 (2006) 408.

[30] C. H. Yang, T. C. Yang, Y. K. Chic, J. Electochem. Soc. 3 (2005) 152. 